\title{
A Case Study for End of Life Reuse and Recycling Survey Methodologies: The Höllentalanger Cottage
}

\author{
Annette Hafner ${ }^{1}$, Stephan $\mathrm{Ott}^{2}$, Eva Bodemer ${ }^{2}$ and Stefan Winter ${ }^{2}$ \\ 1. Department of Civic and Environmental Engineering, Ruhr-university Bochum, Bochum 44801, Germany \\ 2. Department of Civil, Geo and Environmental Engineering, Technische Universität München, Munich 80333, Germany
}

\begin{abstract}
Up to now, reuse and recycling of existing buildings have not been examined widely. This paper discusses the theories, methods and practicalities of buildings' end of life with a main focus on planning and managing reuse and recycling of existing buildings. Our aim is the realistic modelling of theoretical scenarios for end of life based on a case study. The methods of building survey, material classification and documentation for reuse, recycling and disposal of existing constructions are presented. Investigations and calculations were done on an existing cottage in the Alps. The ecologically most beneficial disposal phase of the old wooden hut is our main objective. Critical questions arise from the quality of the material and how it can be extracted, separated and balanced in an appropriate way. A systematic survey of the building by inspection of constructions and materials in iterative steps allows a detailed material balance with condition and property information. This information is crucial for scenarios and material flow analysis of demolished and rebuilt building in environmental system analysis. For future planning, the reuse and recycling of existing buildings should be integrated quite early in the planning process so that we can use the materials in the best way.
\end{abstract}

Key words: Life cycle, end of life, reuse, recycling, material flow, building survey, construction inspection, material analysis.

\section{Introduction}

In consideration of sustainable buildings, closing life cycle loops are becoming more and more important fulfilling ecological demands. Up to now, reuse and recycling of existing buildings have not been examined widely. Reuse and recycling are rarely taken into account in building processes which are centred on the production, erection and operation of buildings. There is a clear need for a life cycle oriented observation of constructions that focus the dismantling and end-of-life of buildings and materials they are made of. Second product life and secondary use of materials are a central goal to fulfill ecological sustainability goals from environmental impact reduction to efficient and careful resource use $[1,2]$. Waste prevention and material efficiency are key performance indicators for sustainable construction products performance requirements as laid down in European Union's

Corresponding author: Annette Hafner, professor, research fields: resource efficient building, sustainable building and building with wood. E-mail: Annette.hafner@rub.de. construction products regulation [3].

This paper discusses the theories, methods and practicalities of buildings' end of life with a main focus on planning and managing reuse and recycling of existing buildings. Furthermore, it demonstrates how to conceptualize and quantify realistic estimations of theoretical end of life scenarios of existing buildings. By using a case study, the quantification of material in the building is possible. Precise surveying methods generate a full picture of the amounts of material types and the dimensions of the building. A broader picture on constructions, material properties and potential chemical treatment needs deeper analysis as used in the field of forensic engineering. Most of the construction was made of wood for structure and cladding.

The scope of the paper is a review of the quantities and qualities of recovered wood from buildings. When discussing the usage of a certain material category, it is also necessary to look at the raw material supply. Sustainable use of wood is preconditioned. With rising consumption of wood as renewable energy source, 
recycling of wooden constructions becomes more important. Alternative sources for construction wood are needed because of the increasing lack of primary resources. Secondary material could offer a chance to avoid a bottleneck in raw material supply. The quantity, dimensions and quality of wood ratio to recover from obsolete buildings are unknown.

As shown in Fig. 1, the consumption of wood for material use will increase slowly in the future, whereas the consumption of wood for energetic use will grow dramatically. In Germany, wood for energetic use has exceeded the material use in 2012 [4, 5].

This fact is the reason of a rising share of fresh wood thermally used and, in the long run, rising cost by a shortage of raw material supply for the timber construction sector in Europe. The use of good quality, recovered solid wood not only as energy source will offer a chance to reduce this economic pressure. Old buildings can provide the necessary dimensions and quantities of construction wood. Other sources for recovered solid wood like packaging or pallets count on much smaller dimensions and are less useful.

There are various studies in EU market, which quantify the usage of wood in market shares [6-8].
Explicit calculations on quantities of recovered wooden material in building sector have not yet been done. No exact evaluation is confirmed on how much recyclable wood exists in our urban mines in general and in which building age class or type of building and how high the potential of reuse or recycling is from this material source [9-11]. There is already a small amount from recovered wood used in the production of particle boards or wood fibre products but it is a small share [9].

Different end-of-life options are useful for different types of construction depending on dismantling and separation properties, hence the purity of fractions. Energy recovery, reuse and material recycling are theoretically possible as the three generic end-of-life scenarios for wooden products $[10,12]$. Practical health related problems exist for end-of-life scenarios of recovered wood. Recycling and even reuse of materials can only be done when the material does not contain harmful substances. Timber for construction purpose has been treated with poisonous chemicals since the beginning of the 20th century to reduce the risk of mould or to impregnate it against insects. This fact decreases the possibility of reuse and even recycling

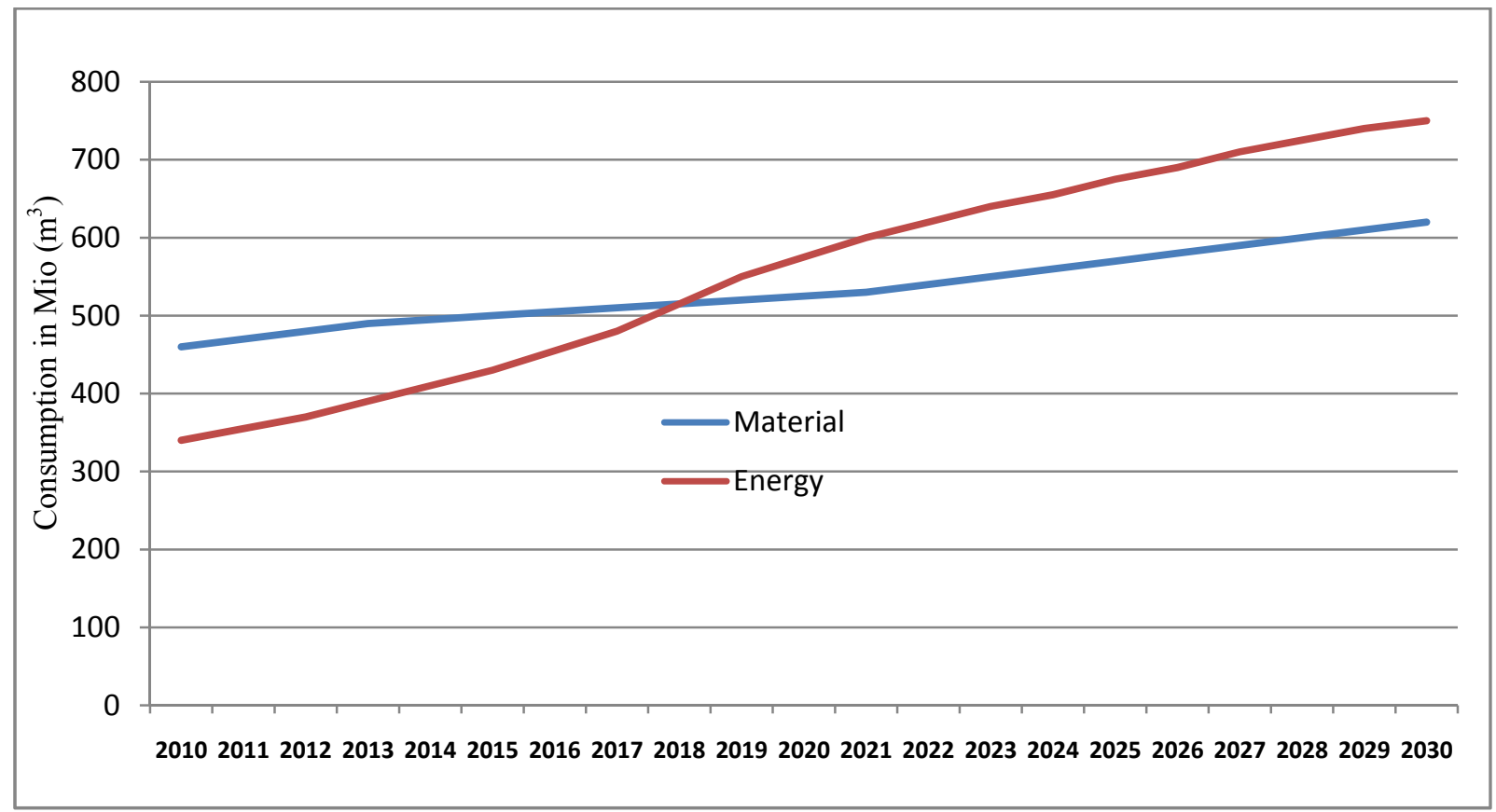

Fig. 1 Consumption of wood for energetic and material use in Europe [4]. 
of reclaimed wood nowadays. For reuse purposes, the contaminated wood has to be identified and its amount has to be quantified. Additionally, the type of chemical treatment has to be analyzed for bio hazardous substances and human-hazard toxicity of treated timber construction. These quantities have to be sorted out and regarded according to the rules for hazardous wastes, in Germany, the recovered wood regulation [13].

Dismantling and reuse of construction parts are problematic because of a wide spread of unplanned demolition. For optimal reuse, the available construction parts have to be identified and classified at least for different end-of-life scenarios. Construction wood and engineered wood products can be dismantled easier than most other parts, because they are used in dedicated layers, and modular assemblies and they are light-weight. The wooden parts are mostly serialized and the dimensions of certain parts are identical. All these themes make wood suitable for reuse $[14,15]$. After the planned dismantling process of removable parts, the rough demolition of monolithic portions can take place.

The aim of the study is a characterization of the state and condition of buildings' end of life by practical methods in order to make realistic assessment of the material fractions to overcome rough estimations and theoretical scenarios for end of life.

In detail, the aims of the study were to:

- gain knowledge on amount and mass of material fractions. Answer the question on how much wood is contained in an Alpine cottage;

- estimate material fractions on basis of drawings and find out discrepancy to real measurements on site;

- gain knowledge on amount of contaminated material;

- find out building quality of old timber constructions.

Exemplary investigations and calculations are done on a case study, an existing cottage in the Alps, which is located in a sensitive natural environment. The ecologic most beneficial disposal phase of the old Alpine hut is our main objective.

\section{Understanding State and Condition for End-of-Life of Building}

\subsection{Case Study: Höllentalanger Cottage}

The existing cottage is to be rebuilt and has to be dismantled and demolished in a planned way. The owner, the Munich chapter of the German Alpine Club, needs detailed information about the building masses. He has to tear down the building and to treat all demolition waste carefully due to the site being located in a nature reserve. Additionally, all material has to be brought to the valley by helicopter flights and, therefore, masses are a very important parameter for the construction costs. Hence, as much material and components should be reused and selected for recycling on-site. Critical questions arise from the quality of the material (moisture content, chemical treatment, moulder, etc.).

The Höllentalanger cottage (Fig. 2) is located in the northern Alps close to Garmisch-Partenkirchen. It is situated at a height of $1,387 \mathrm{~m}$ above sea level and can only be reached through a small and steep foot path. For logistics and supply items, an additional cable car with a maximum payload of $200 \mathrm{~kg}$ exists. Water and energy supply are organized self-sufficient for the cottage. The energy for operating and especially the kitchen of the cottage are supplied by a diesel engine which is run by bio diesel provided with the cable car.

The cottage contains bedrooms for 80 people, the flat for the landlord, sanitary facilities, a kitchen and a restaurant. The most important issue is a huge amount of visitors who climb up the Höllental gorge each summer.

The existing fabric of the cottage does no longer fulfil today's technical and functional requirements. Additionally, it lacks protection from avalanches, ergonomic work environment, spatial and architectural potential to reuse the existing substance in its actual state. 


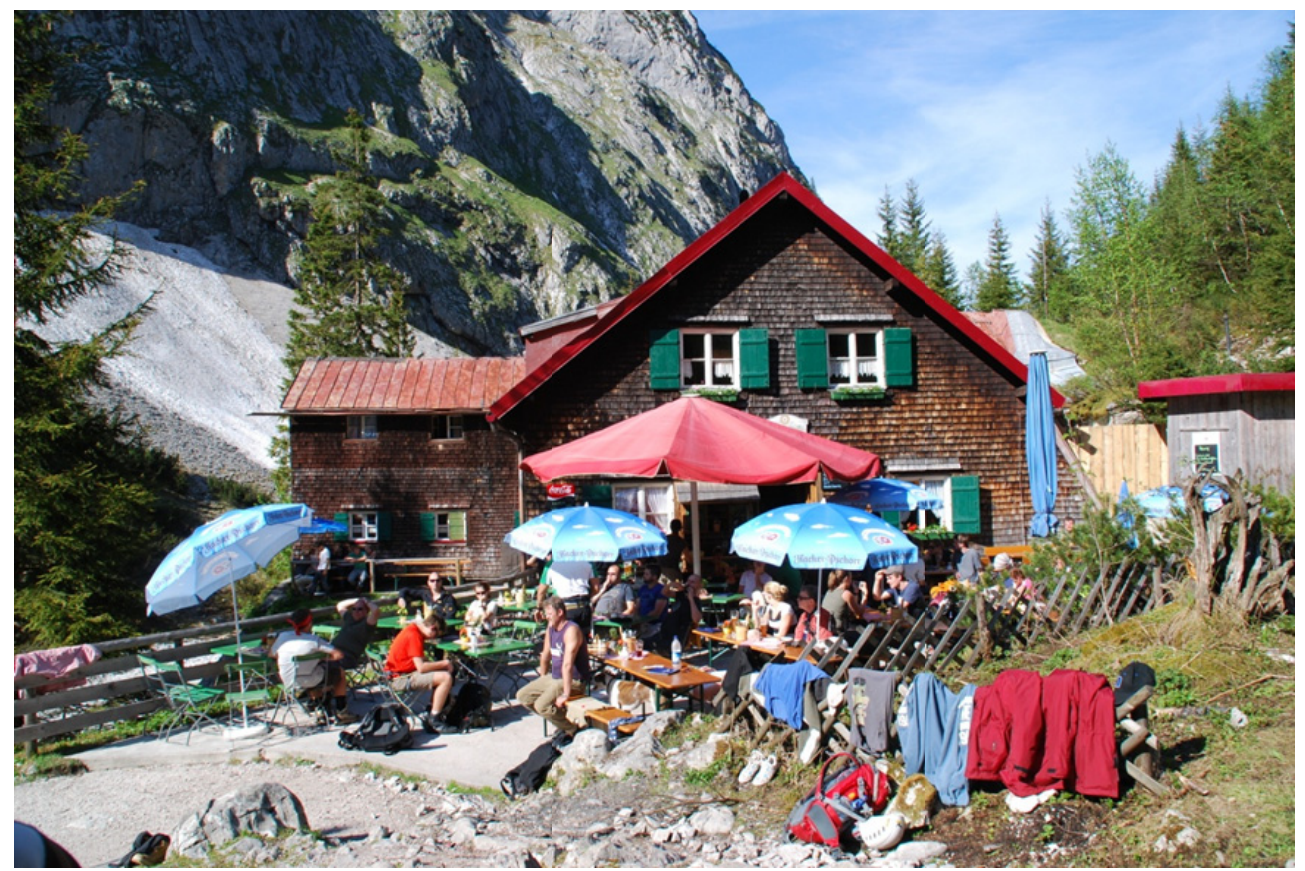

Fig. 2 Höllentalanger cottage, west facade of second extension phase in 1925.

The cottage is an example for mixed construction with a long life cycle with numerous repair intervals, changes, building extensions and a conglomerate of different materials which is typical for old buildings. The goals can only be fulfilled when material fractions and total amount of wood are known as well as the way to do smart dismantling with a high ratio of recovered material. It requires a thorough survey of the existing building and construction in order to gather in-depth information for further conceptualization of end of life scenarios.

\subsection{Methods of Information Collection}

Here, the combination of building survey, classification of components, parts, materials and documentation into a consistent general methodology for reuse, recycling and disposal of existing constructions are presented. Used methods for that were: historic research based on existing drawings and archival material to identify, date and limit building phases. In-situ construction surveying was undertaken to measure and verify exact sizes and to check the jointing and tectonics for dismantling of the building, as well as the technical status of the material [16].
Further methods of forensic engineering comprise the testing of material samples to examine it for hazardous substances [17]. These three requirements can be compiled into a building condition and quantity structure as shown in Fig. 3. It is a step-by-step process where each phase of the examination supplies additional information and increases the level of detail concluding a comprehensive building and construction description.

\subsection{Extent of Survey and System Boundaries}

The extent of the survey considers the construction of the whole building and all attached materials for foundation: walls, floors, and roof. The building is geometrically verified in full exterior dimensions and from foundation to the roof top. The information level of the construction varies from the primary load bearing construction, related functional layers and claddings, surfaces treatments of interior and exterior down to substances analysis and quality of parts testing. All technical equipments or building systems like heating, kitchen equipments, water pump as well as flexible interior and furniture are suspended from our examinations. Building services materials are 


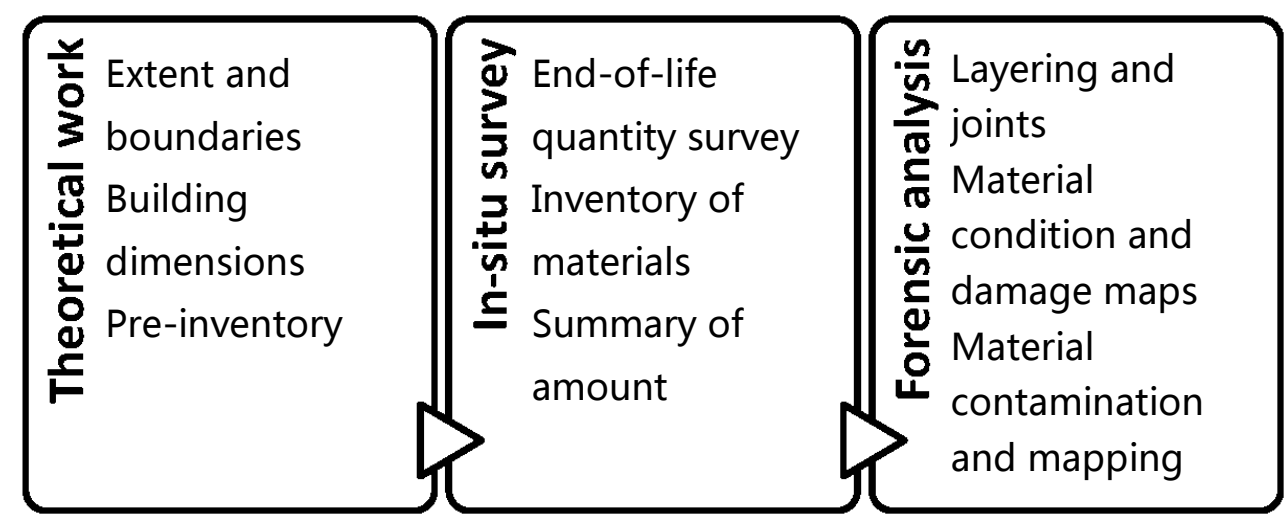

Fig. 3 Subdivided concept and process steps with information structure as outcome.

excluded although they contain copper, ferrous material and other metals which are interesting from a resource and economic point of view. The main interest was on the construction itself, hence the landscaping with, for example, stone paving or parapet walls in circumference of the building does not count to the inventory of materials.

\subsection{Survey and Forensic Analysis of Inventory}

Basis for the examinations is an overall inventory analysis and a documentation of existing construction with classification of material types.

The on-site survey work was divided into two parts. The first part was the in-situ survey which helped to verify dimension, material types and masses, and drawing of construction joints. The second part was the forensic analysis of building and construction state. Basic instruments for forensic methods were the drawings and records of damages of construction and material layering. The construction is further investigated with focus on detailed information about connections and their additional materials like screws, fasteners and internal layers. Also, it looked at the way of assembly. A detailed examination of materials is part of tracking of possible use of harmful substances and treatment of wood with chemicals. The timeline information about maintenance and interviews with staff and landlord helped in localizing the areas of interest.

There are several steps needed to iteratively form an entire picture of material obsolescence knowledge from the bits and pieces from various information sources. Normally, it starts with old drawings as far as they exist, but often they show an old state of the building and are not detailed enough to gather thorough information at the desk. Nevertheless, old plans can provide useful information of building dimensions and a pre-inventory of constructions. Further in-situ surveying methods complement, improve and verify the first stage. They add a more detailed room book where each room is documented not only with function, dimensions, surface materials, but also with sketches of constructions behind the linings and photographs. Main part still remains the completion of the inventory with in-situ information. The next level of results should give an insight in the deviation of the first estimation of material mass and volume from actually measured amount. The quality and the state of the wood cannot be surveyed remotely. Damages as well as treatment of material are not documented but are essential information for further decisions and modelling of end-of-life scenarios.

\section{Examinations}

\subsection{Historic Research on Archival Material}

Initially, a theoretical review has been conducted according to existing drawings like the ones in Fig. 4 and Table 1. This approach enables the examination of all parts of the building including hidden built-in parts. The results include the foundation as well as 
inaccessible constructions whose dimensions can only be guessed when they are buried behind claddings or remain inaccessible for other reasons.

The goal of the theoretical evaluation is to get structured lists of the building and its parts. Sometimes it is possible to acquire absolute values of areas and cubature of buildings and rough list of materials from archival sources.

This initial part of the inventory is of theoretical nature and based on research in archives for information about the history of the cottage. The extension stages of the building cover the lifecycle with repairs, refurbishments and changes in existing parts. The investigation of archival material first results in a timeline, dating the phases and the extent of each stage of construction. Timeline information was enhanced with findings on construction types and materials and maintenance information. With old drawings and sections, the construction of the building (material layers) is calculated. Through connection of material layers with space for each construction, the amount of material is determined. Each material gets separately counted. All materials get allocated by their specific weight and, additionally, the recycling or end-of-life

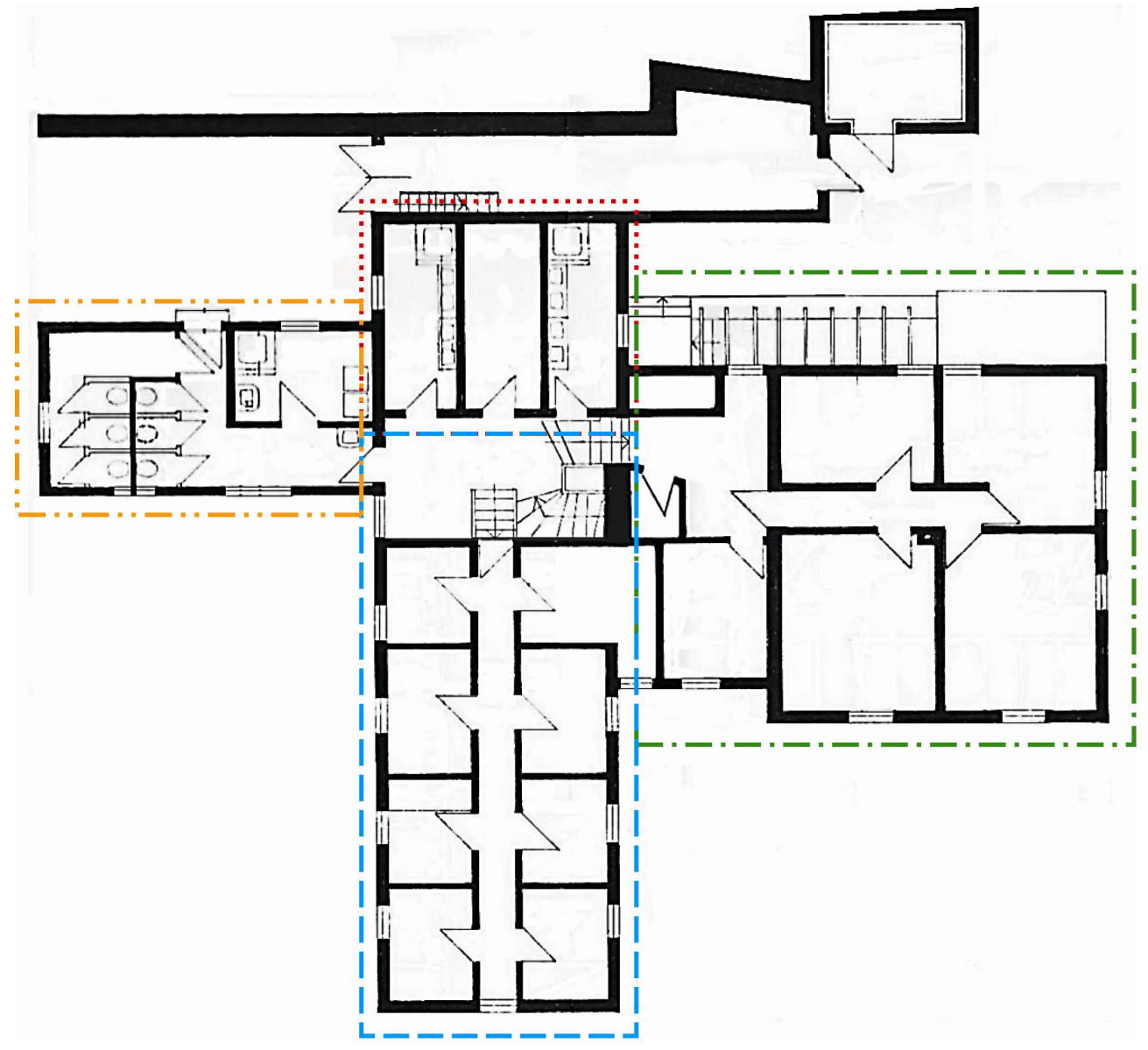

Fig. 4 Ground floor plan showing construction stages of Höllentalanger cottage.

Table 1 Different stages of building activities and extensions of cottage.

\begin{tabular}{lll}
\hline Year & Building stage and function & Main construction materials \\
\hline 1893 & Refuge (dotted line) & Log house \\
1909 & $\begin{array}{l}\text { Extension with a two-storey dormitory building } \\
\text { (dashed line) }\end{array}$ & $\begin{array}{l}\text { Wooden post and beam construction on a foundation made from } \\
\text { coarse gravel }\end{array}$ \\
1925 & Extension of kitchen and restaurant (dash-dot line) & Wooden post and beam construction erected on a stone masonry cellar \\
1963 & Extension of sanitation facilities (dash-dot-dot line) & Stone building with masonry walls from light-weight concrete blocks \\
\hline
\end{tabular}


Table 2 Survey of floor areas and volumes of the cottage verified in-situ.

\begin{tabular}{lcl}
\hline & Numbers & Unit \\
\hline Gross external volume & 1,650 & $\mathrm{~m}^{3}$ \\
Net floor area & 511 & $\mathrm{~m}^{2}$ \\
Use space & 446 & $\mathrm{~m}^{2}$ \\
Built area & 331 & $\mathrm{~m}^{2}$ \\
Envelope area & 1,381 & $\mathrm{~m}^{2}$ \\
Roof area & 471 & $\mathrm{~m}^{2}$ \\
Building footprint & 331 & $\mathrm{~m}^{2}$ \\
Exterior walls & 477 & $\mathrm{~m}^{2}$ \\
Basement/cellar & 48 & $\mathrm{~m}^{2}$ \\
Fire wood storage & 54 & $\mathrm{~m}^{2}$ \\
\hline
\end{tabular}

possibilities. Material masses and volumes are done as second step according to existing drawings to get deeper insight in quantities and material usage.

Furthermore, it gives information about fractions of material for the three disposal scenarios introduced above. In Table 2, the floor areas of the cottage are outlined. The deviation between the plan and reality has shown minor differences in this case.

\subsection{In-Situ Inspections and Documentation}

Through survey on-site, the result of the theoretical examinations is verified as far as the construction has been accessible. In parts with zero information, the construction was inspected through openings or by removal of claddings. In areas where interventions are forbidden, they have been inspected with an endoscope. Small scale drawings and sketches of components and joints are done to improve the documentation. Modifications and systematic deviations to the existing drawings are detected and also documented.

Pre-inventory tables of construction elements in hierarchical order show all surface areas and are combined with a components list, materials description and the amounts of the materials in volume and mass. All material layers get checked on their thickness. The area of each used construction is cross-checked through exact measurements on site. Additionally, the damages of construction are documented and samples of material (mostly wooden) are taken to test the content on harmful substances.
Additional to components list, moisture in the different parts is measured to identify wood damage. Damages of construction and materials were traced out and material samples of four different constructions were taken to be analysed in the laboratory.

\subsection{Forensic Research and Material Testing}

Material samples were taken for analysation in the laboratory. Knowledge on chemical treatment and possible contamination of wood and other material is essential information for further waste treatment. Potential treatments are found by inspecting surfaces and openings of constructions. Samples of surface material from timber constructions (at least $5 \mathrm{~mm}$ thickness and $50 \mathrm{~mm} \times 50 \mathrm{~mm}$ of size) were analysed to test for harmful substances, the types of substances were also determined. Wooden parts can only be reused if no harmful substances are detected in the material according to the national waste wood regulation.

The material samples were taken with their documentation to the Laboratory of the Wood Science Department (Holzforschung München), which is part of the Technische Universität München and were chemically analyzed there.

Harmful substances like PAK (polycyclic aromatic hydrocarbon) and PCP (pentachlorophenol) in coatings were detected by pyrolysis and spectroscopy. These components are classified beyond normal waste categories as PCP contaminated. This means special treatment according to waste wood ordinance. Thereby, reusing and recycling is not possible without a careful separation of the toxic and non-toxic materials. Results of the analysis showed that main parts of the timber construction could be reused as building components. Only parts of the outside facade and materials included in the building erected in the 1960s contain critical substances. The amount is $7.1 \%$ of total wood mass. Most material from the original cottage is untreated and free of harmful substances. It is also in good and dry condition. 
The Höllentalanger cottage is an example of buildings primarily built from wooden material. Calculations of the material included in the building show the quantity of various materials. Analysis of material fractions in mass and volume shows a high percentage of mineral based material in the cottage. With very simple wooden constructions, wooden material reaches a share of $38 \%$ in volume and a mass of $14 \%$. The wooden material includes load bearing construction, flooring, formwork and shingles. Main mass is $63 \%$ concrete/stone in foundation, ground floor and some walls. Only $1 \%$ of material mass is the metal roof. Complete analysis of construction is shown in Fig. 5.

Fig. 6 shows the share of harmful substances in the wooden material divided up in different building parts. The amount of contaminated wood is small. The highest share is in the facade cladding and in a few interior claddings.

The result of the analysis shows that mostly solid wood from cottage (built nearly a hundred years ago) is reusable. About $50 \%$ of the beams are available in reasonable dimensions from $80 \mathrm{~mm}$ to $240 \mathrm{~mm}$. Mainly, the oldest material logging up to $320 \mathrm{~mm}$ diameter of
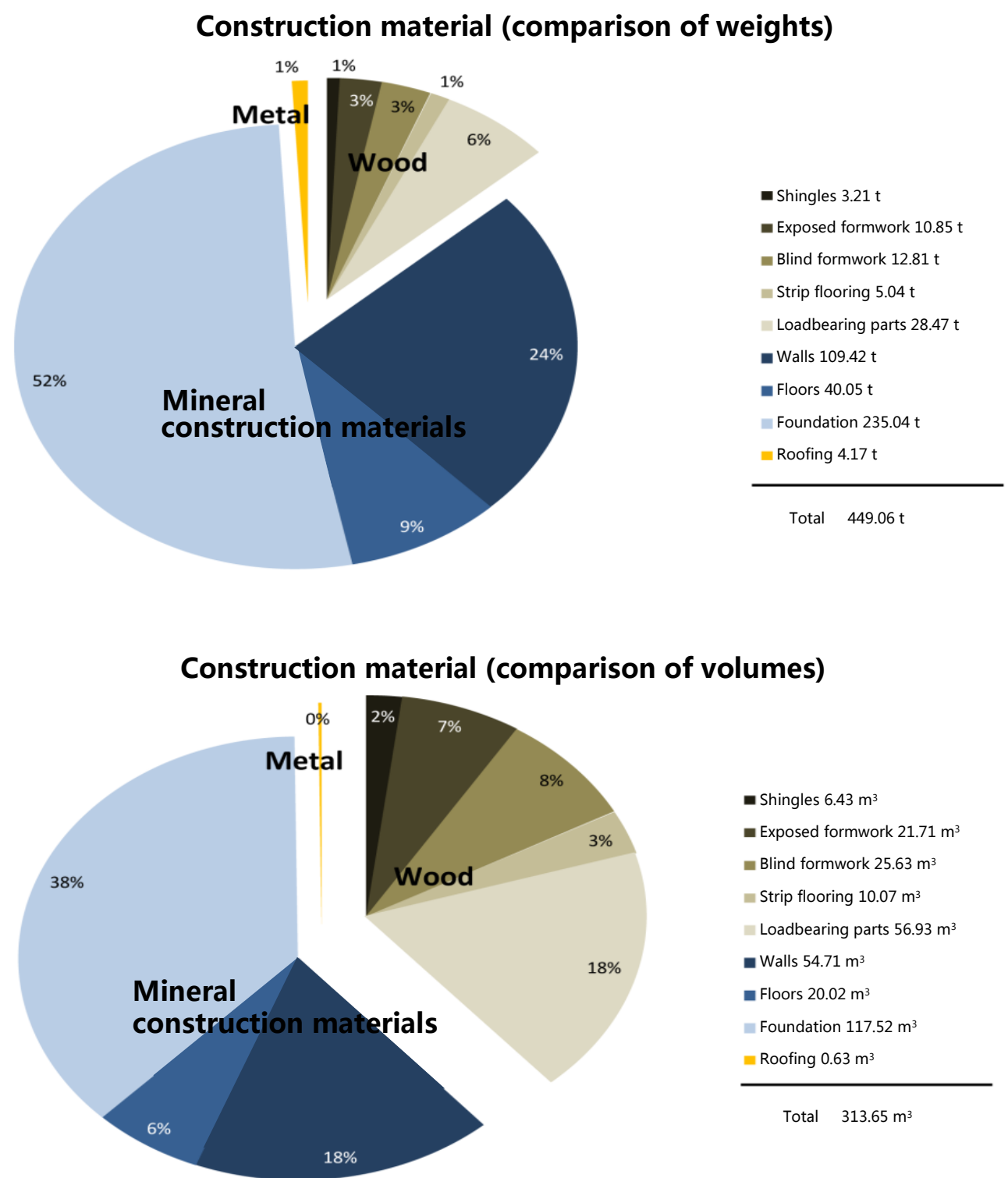

Fig. 5 Construction material—different fractions. Comparison of mass and volume. 
Pollution level of the wooden construction materials (all data in $\mathrm{m}^{3}$ )

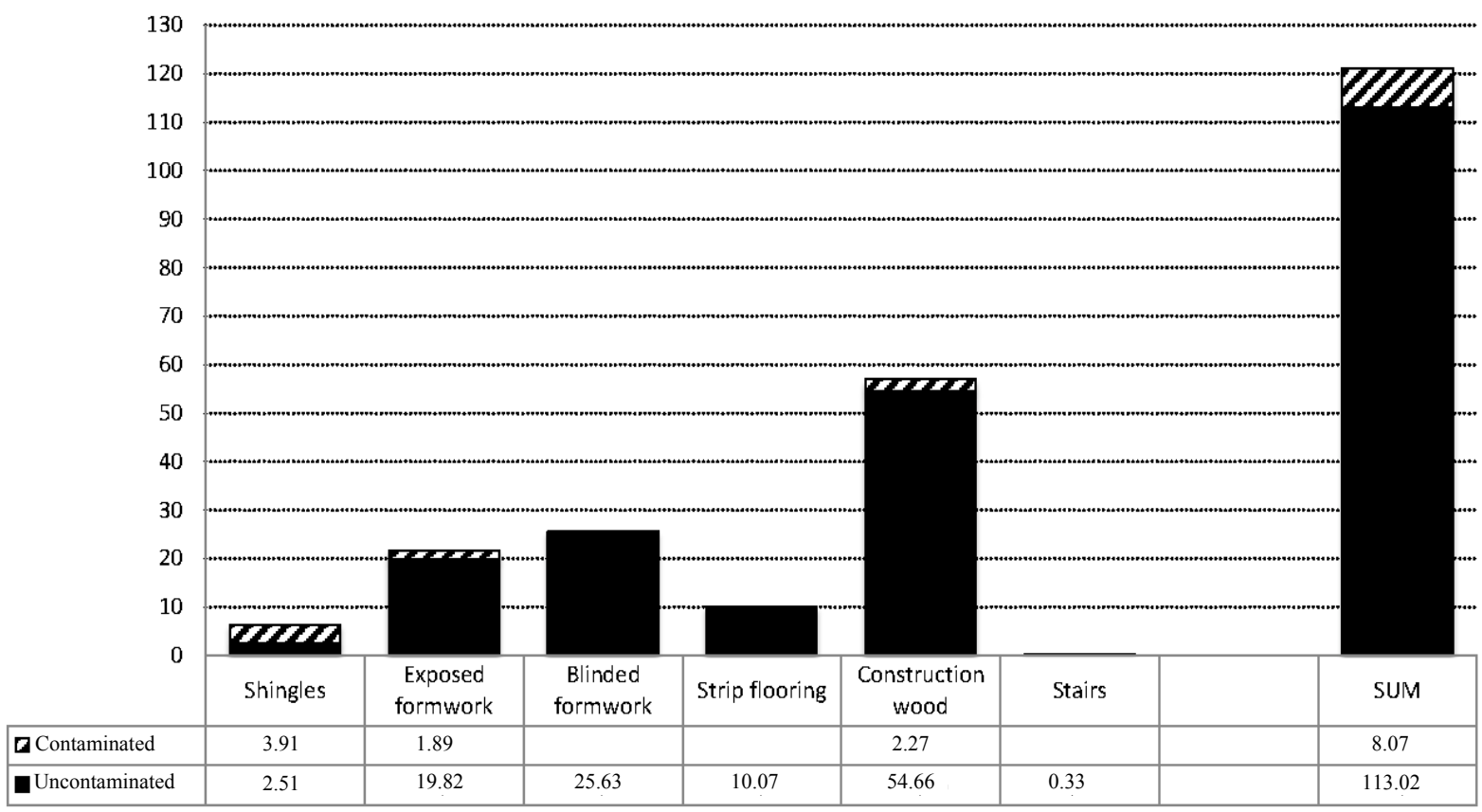

Fig. 6 Share of harmful substances in construction (hatched).

the primeval hut, is of good quality. Reusing the material for the new design of the Höllentalanger cottage was not analyzed in depth as the planning of the cottage is already nearly finished and a new timber structure is planned with cross laminated timber.

In order to use the material in the best way, the reuse and recycling of existing buildings have to be integrated quite early in the planning process. Small scale drawings also show how components are constructed and how jointing is done. This information is useful for dismantling.

\section{Conclusions}

For recycling of existing buildings, exact calculation of actual mass and volume as well as building condition is necessary. Therefore, drawings (as built) help to calculate overall quantities. They need to be checked on-site with survey. On-site survey focuses on quality of materials. The quality of wood and the use of harmful substances can be identified only in-situ. Although main parts of the survey have to be carried out on-site, the work can be prepared and carried out efficiently with the help of theoretical research.
Forensic analyses are important for choosing material for recycling without introducing harmful substances in the recycling process. For reuse, the classification system has to be improved to come in line with the reclaimed wood classes regarding the contamination. This could be difficult because the way of reuse is unclear and needs further development.

Although the cottage is a wooden building, it only contains about $38 \%$ in volume or $14 \%$ in mass wooden material, which is around $60 \mathrm{t}$. In detail, the study showed that old drawings are helpful to detect material layers and constructions. In reality, some of the construction (around 20\%) is different to the original drawings. Exact measurements on site are needed to verify material amounts.

As a case study, the Höllentalanger cottage reveals that a more than 120-year-old wooden construction is still in very good condition and could be reused in large parts. In parts where no maintenance and repairs were conducted, for example, running water around broken rain gutters, the wood is mouldy and cannot be reused. Harmful substances in paints cause problems for recycling. Here, exact material testing is necessary. 
The amount of contaminated material was around 7\% of wooden fraction and mainly found in painted shingles.

In general, the conclusion can be drawn that this Alpine cottage is an example of a simple building with a minimized construction, which allows a high level of reuse. Reduced material fractions make separation easier and limit economic effort.

\section{Acknowledgments}

This paper was based on the bachelor thesis of Mathias Woznik and on-site survey with students in summer, 2012. Material tests were kindly made available by the Holzforschung München.

\section{References}

[1] Waste Directive, No 2008/98/EC of the European Parliament and of the Council of 19 November 2008 on Waste and Repealing Certain Directives, European Commision, 2008.

[2] A. Zuser, H. Rechberger, Considerations of resource availability in technology development strategies: The case study of photovoltaics, Resources, Conservation and Recycling 56 (1) (2011) 56-65.

[3] Construction Products Regulation, No. 305/2011 of the European Parliament and of the Council of 9 March 2011 Laying Down Harmonised Conditions for the Marketing of Construction Products and Repealing Council Directive 89/106/EC, Construction Products Regulation, 2011.

[4] U. Mantau, U. Saal, K. Prins, F. Steierer, M. Lindner, H. Verkerk, et al., Real Potential for Changes in Growth and Use of EU (European Union) Forests-EU Wood [Online], Final 2010, http://ec.europa.eu/energy/renewables/studies/doc/bioene rgy/euwood_final_report.pdf (accessed Jan. 25, 2013).

[5] Holzzentralblatt, Mehr Holz verbrannt als verarbeitet, Energiepreise und Politik verändern Holznachfrage(More wood burnt than manufactured, energy prices and politics change wood demand), in Holzzentralblatt, Leinfelden-Echterdingen, $\quad$ DRW-Verlag 8 (Dr.Weinbrenner Publishers), 2012. (in German)

[6] A. Lang, Charakterisierung des Altholzaufkommens in Deutschland, Rechtliche Rahmenbedingungen-Mengenpotenzial-Materialkenn werte (Characterization of Wastewood in Germany, Legal Framework, Potential Amounts, Material Properties), Mitteilungen der Bundesforschungsanstalt für Forst- und
Holzwirtschaft Nr. 215 (Information Nr. 215 of Federal Research Institute for Rural Areas), Kommissionsverlag Buchhandlung Max Wiedebusch, Hamburg, 2004. (in German)

[7] H. Weimar, Empirische Erhebungen im Rohstoffmarkt am Beispiel der neuen Sektoren Altholz und Großfeuerungsanlagen (Empirica linvestigations on raw material market with the example of waste wood and combustion plants), in: Sozialwissenschaftliche Schriften zur forst-und Holzwirtschaft, Band 9 (Socioscientific Writings on Forestry, Book 9), Internationaler Verlag der Wissenschaften, Frankfurt am Main, 2009. (in German)

[8] U. Mantau, Rohstoffknappheit und Holzmarkt (Raw material scarcity and wood market), in: O. Depenheuer, B. Möhring (Eds.), Waldeigentum. Hrsg, Springer-Verlag, Berlin, Heidelberg, 2010. (in German)

[9] U. Mantau, H. Weimar, T. Kloock, Standorte der Holzwirtschaft-Holzrohstoffmonitoring: Altholz im Entsorgungsmarkt-Aufkommens und Vertriebsstruktur 2010 (Locations of Wood sector-Wood Raw Material Monitoring: Recovered Wood in Waste Market-Amount and Distribution Structures 2010), Final report, Hamburg, 2012. (in German)

[10] M. Klinglmair, J. Fellner, Urban mining in times of raw material shortage, Journal of Industrial Ecology 14 (4) (2010) 666-679.

[11] R. Obernosterer, P.H. Brunner, Urban metal management: The example of lead, Water, Air and Soil Pollution 1 (3-4) (2001) 241-253.

[12] A. Merl Reuse, recycling and energy generation of recovered wood from building construction-Showcase Vienna, in: Proceedings of the 3rd European Cooperation in Science and Technology E31 Conference, Klagenfurt, 2007, pp. 237-251.

[13] Verordnung über Anforderungen an die Verwertung und Beseitigung von Altholz Altholzverordnung-AltholzV (Ordinance on the Management of Waste Wood), Government of Germany for Management of Waste Wood, 2012. (in German)

[14] M. Kuittinen, A. Ludvig, G. Weiss, Wood in Carbon Efficient Construction-Tools, Methods and Applications, CEI-Bois, Brüssel, 2013.

[15] A. Hafner, S. Ott, S. Winter, Recycling and end-of-life scenarios for timber structures, in: S. Aicher, H.W. Reinhardt, H. Garrecht (Eds.), Materials and Joints in Timber Structures, Springer, London, 2014, pp. 89-98.

[16] W.H. Irvine, F. MacLennan, Surveying for Construction, McGraw-Hill Education, New York, 2006.

[17] K.L. Carper, Forensic Engineering, 2nd ed., Chemical Rubber Company Press, New York, 2002. 